\title{
Maltodextrin improves physical properties and volatile compound retention of spray-dried asparagus concentrate
}

\author{
Joanne W. Siccama ${ }^{\mathrm{a}}$, Eirini Pegiou ${ }^{\mathrm{b}}$, Lu Zhang ${ }^{\mathrm{a}}$, Roland Mumm ${ }^{\mathrm{c}, \mathrm{d}}$, Robert D. Hall ${ }^{\mathrm{b}, \mathrm{c}, \mathrm{d}}$, \\ Remko M. Boom ${ }^{\text {a }}$, Maarten A.I. Schutyser ${ }^{\text {a, }}$ \\ ${ }^{a}$ Laboratory of Food Process Engineering, Wageningen University and Research, Wageningen, the Netherlands \\ ${ }^{\mathrm{b}}$ Laboratory of Plant Physiology, Wageningen University and Research, Wageningen, the Netherlands \\ ${ }^{\mathrm{c}}$ Business Unit Bioscience, Wageningen University and Research, Wageningen, the Netherlands \\ ${ }^{\mathrm{d}}$ Netherlands Metabolomics Centre, Leiden, the Netherlands
}

\section{A R T I C L E I N F O}

\section{Keywords:}

Asparagus

Aroma encapsulation

Spray drying

GC-MS

Maltodextrin

\begin{abstract}
A B S T R A C T
Traditional hot air drying of asparagus is known to lead to a powder with a poor aroma profile. We here concentrated asparagus juice into asparagus concentrate $(21.7 \% \mathrm{w} / \mathrm{w})$ and spray-dried it with maltodextrin DE12 as carrier agent to improve the volatile profiles of asparagus powder and to valorise fresh asparagus sidestreams. We performed headspace GC-MS with untargeted metabolomics to assess the overall metabolite profile of the spray-dried asparagus powders and identified 70 volatile compounds. The maltodextrin content was positively correlated to the retention of an asparagus key odorant 1-octen-3-ol, as well as other alcohols and aldehydes. Nevertheless, drying conditions had limited effect on the volatile retention of the powders. Moreover, higher outlet temperatures increase the presence of volatiles that were formed during drying, such as 3-methylthio-propanal. From our analyses, it was further found that an increased concentration of maltodextrin was correlated to a lower moisture content, a higher glass transition temperature $\left(\mathrm{T}_{\mathrm{g}}\right)$ and a narrower size distribution of the spray-dried powders. The $\mathrm{T}_{\mathrm{g}}$ of all powders was described with the Gordon-Taylor equation for multicomponent mixtures, and we found a minimum weight fraction of $0.67(\mathrm{w} / \mathrm{dw})$ maltodextrin required to obtain glassy asparagus powder for storing at ambient conditions.
\end{abstract}

\section{Introduction}

Asparagus (Asparagus officinalis) is a popular vegetable consumed all over the world. The production of asparagus comprised 9.1 million tons globally in 2018 (Knoema, 2019). While the green form is most common, the white form is appreciated by its consumers because of its structure and flavour profile. White asparagus flavour has been the topic of several studies in the past (Tressl, Holzer, \& Apetz, 1977, ; Ulrich et al., 2001), which has led to the identification of some key aroma components in cooked asparagus (Pegiou et al., 2019).

After harvesting, approximately one-third of the lower part of the white asparagus spear is cut off because of its woody texture and to standardize the length of the spears for the market (Zhang et al., 2014). A significant waste stream is thus generated, which could potentially be utilised as a food ingredient, for example in the form of asparagus powder for instant soups. Conventionally, commercial asparagus powder is made by air-drying (i.e. tray drying) small pieces of asparagus spear followed by milling (Karam et al., 2016; Nindo et al., 2003). However, the drying process alters the volatile profile of asparagus powder. Some aroma compounds of asparagus are lost during drying, whereas some other asparagus key odorants can be formed upon drying, including sulphur-containing compounds such as dimethyl sulphide (Nijhuis et al., 1998; Ulrich et al., 2001). Ideally, the formation of those key odorants should be suppressed during drying of asparagus powder to prevent aroma loss upon storage. To ensure flavour stability, artificial flavouring agents are added to the asparagus powders. These flavouring agents may not fit in a formulation targeted to be perceived as natural and healthy by consumers (Bearth et al., 2014; Eiser et al., 2002; Shim et al., 2011). Therefore, to obtain asparagus powders with better aroma profile, new drying strategies need to be developed. These strategies include the selection of a drying method as well as the optimisation of this drying method.

Spray drying has been widely used to encapsulate flavour compounds in vegetable powders (Verma \& Vir Singh, 2015). Thus,

\footnotetext{
* Corresponding author.

E-mail address: maarten.schutyser@wur.nl (M.A.I. Schutyser).
} 
asparagus powder with improved flavour profile may be obtained by using spray drying (Siccama et al., 2019). More specifically, asparagus juice can be pressed and concentrated from the side stream and then spray-dried to produce asparagus powder. However, direct spray drying of this concentrate is problematic due to stickiness issues leading to fouling in the drying chamber. This is because asparagus concentrate is rich in small sugars that have a low glass transition temperature $\left(\mathrm{T}_{\mathrm{g}}\right)$. Hence, the addition of carrier agents with a high $\mathrm{T}_{\mathrm{g}}$, e.g. maltodextrins with a low dextrose equivalent (DE), to the concentrate can be used to avoid fouling and to improve powder quality (Verma \& Vir Singh, 2015).

During spray drying, the liquid feed is atomized into small droplets and exposed to hot air. Initially, the drying is externally limited, but an internal moisture gradient evolves when the surface of the droplet reaches a critical moisture concentration. After this, a semi-permeable "skin" is formed on the droplet surface, which allows further removal of water but hinders the release of larger volatile aroma compounds (Coumans et al., 1994). Loss of volatile compounds mainly occurs before this "skin" is formed, i.e. during the constant drying rate period (Thijssen, 1971). Hence, a shorter constant rate period is favourable for aroma retention during spray drying. Specifically, addition of hydrolysed starches (i.e. maltodextrins) can encapsulate flavours by faster skin formation and increase the $\mathrm{T}_{\mathrm{g}}$ of the mixture (Madene et al., 2006; Zuidam \& Heinrich, 2010). Besides, adding high molecular weight carrier agents could reduce the diffusion of flavour compounds from within the drying matrix to the droplet surface until the semi-permeable skin is formed (Anandharamakrishnan \& Padma Ishwarya, 2015). In general, carriers with low viscosity at high solids content such as maltodextrin are desired, because it allows for relative higher concentrations (Reineccius, 2004).

Furthermore, the drying conditions (e.g. inlet temperature) influence volatile retention during spray drying. For example, a higher inlet temperature may improve aroma retention because it shortens the constant rate period (Coumans et al., 1994; Reineccius, 2004). Nevertheless, a too high inlet temperature can lead to worse aroma retention by inducing excessive bubble formation and surface cracks (King, 1995).

Thus, both carrier choice and drying conditions affect the volatile profile of spray-dried powders. In this study we employ mass spectrometry-based metabolomics, being an emerging technique for the characterization of volatile profiles in foods (Diez-Simon et al., 2019). To the best of our knowledge, the combination of spray drying experiments and gas chromatography-mass spectrometry (GC-MS) analysis of the overall volatile profile of spray-dried powders following a metabolomics approach has not been reported before. Therefore, we here aim to assess the volatile profile and the retention of key volatiles in spray-dried asparagus concentrate as influenced by the addition of maltodextrin DE12 and drying conditions. Maltodextrin DE12 was selected since Bangs and Reineccius (1982) found that the overall retention of twelve volatile compounds was maximised for maltodextrins with DE 10-15. In brief, asparagus juice was extracted from a white asparagus waste stream (i.e. bottom of the spears), concentrated with reverse osmosis and mixed with maltodextrin DE12 at different solids ratios. Subsequently, the solutions were spray-dried at different inlet and outlet temperature combinations. The powders were evaluated in terms of physical properties (i.e. moisture content, $\mathrm{T}_{\mathrm{g}}$, particle size distribution and particle morphology) and their volatile profile. The volatile profiles were analysed by headspace solid-phase microextraction (HS-SPME), followed by gas chromatography-mass spectrometry (GC-MS).

\section{Materials \& methods}

\subsection{Sample preparation}

Raw fresh asparagus cut-offs (Asparagus officinalis) were kindly provided by Teboza BV (Helden, the Netherlands). Concentrated asparagus juice was prepared from these asparagus cut-offs by
Wageningen Food Biobased Research (Wageningen, the Netherlands). Specifically, asparagus juice was pressed and centrifuged to remove any fibres. The juice was concentrated to a factor of 5.6 with reverse osmosis into a final dry matter content of $21.7 \% \mathrm{w} / \mathrm{w}$. The sugar composition of the asparagus concentrate consists of $78 \mathrm{mg} / \mathrm{ml}$ fructose, $72 \mathrm{mg} / \mathrm{ml}$ glucose and $8 \mathrm{mg} / \mathrm{ml}$ sucrose, which was determined with highperformance liquid chromatography (HPLC) using a Shodex KS-802 $8.0 \times 300(\mathrm{~mm})$ column. The column was operated at $50{ }^{\circ} \mathrm{C}$ and connected to a refractive index detector (Shodex RI-501). Milli-Q water was used as eluent with a flow rate of $1 \mathrm{ml} / \mathrm{min}$. The concentrate was aliquoted into test tubes and stored at $-20^{\circ} \mathrm{C}$ before the experiments. For every experiment, a new tube was taken from the freezer and the concentrate was defrosted in the fridge at $4{ }^{\circ} \mathrm{C}$ for $18-20 \mathrm{~h}$.

Maltodextrin DE12 (MD12, Roquette, France) was added to the concentrated asparagus juice to formulate the mixtures for the spray drying experiments shown in Table 1 . The mass ratios between asparagus solids and maltodextrin in the mixtures were adjusted to $2: 1,1: 1$ and $1: 2$, respectively. In addition, one sample with a $1: 2$ ratio was diluted to obtain the same total solids content as the 1:1 ratio sample. This sample will be referred to as $1: 2^{*}$. Pure concentrated asparagus juice was used as a reference sample (i.e., 1:0). All the samples were stirred at room temperature at $400 \mathrm{rpm}$ for $1 \mathrm{~h}$ before each spray drying experiment.

\subsection{Spray drying experiment}

The maltodextrin-asparagus concentrate mixtures were spray-dried with a Model B-290 mini spray dryer (BÜCHI Labortechnik AG, Flawil, Switzerland). The aspirator rate was $90 \%$ which corresponded to an airflow of $35 \mathrm{~m}^{3} / \mathrm{h}$. To investigate the effect of the maltodextrin concentration on the properties of spray-dried powders, samples (1:0, 2:1, $1: 1$ and 1:2) were dried under the same conditions, i.e., the inlet air temperature $\left(\mathrm{T}_{\text {in }}\right)$ was $160{ }^{\circ} \mathrm{C}$ and the outlet air temperature $\left(\mathrm{T}_{\text {out }}\right)$ was $90-95{ }^{\circ} \mathrm{C}$. The speed of the peristaltic pump was adjusted to $3-10.5 \mathrm{ml}$ feed/min to ensure the desired outlet air temperature. In addition, the sample with a ratio of $1: 1$ was dried in two inlet/outlet combination experiments (i.e., $\mathrm{T}_{\text {in }} / \mathrm{T}_{\text {out }}=180{ }^{\circ} \mathrm{C} / 90{ }^{\circ} \mathrm{C}$ and $180{ }^{\circ} \mathrm{C} / 105{ }^{\circ} \mathrm{C}$ ), to investigate the effect of drying conditions. For both combinations, the feed rate was adjusted to reach the desired $\mathrm{T}_{\text {out }}$. For every condition (i.e. ratio and drying condition), three independent spray drying experiments were performed and the asparagus powders were collected at the outlet of the spray dryer for further analysis.

\subsection{Moisture content}

Spray-dried powder $(\sim 0.5 \mathrm{~g})$ was placed in a hot air oven (Binder, Tuttlingen, Germany) to determine its moisture content. The powder was weighed before and after drying at $105{ }^{\circ} \mathrm{C}$ overnight, and the moisture content of the powder was calculated on total basis. Measurements were carried out in triplicate.

Table 1

Overview of the experimental design for spray drying of asparagus juice concentrate and maltodextrin mixtures.

\begin{tabular}{|c|c|c|c|c|c|}
\hline \multirow{2}{*}{ Sample } & \multicolumn{3}{|c|}{ Sample composition } & \multicolumn{2}{|c|}{ Drying condition } \\
\hline & $\begin{array}{l}\text { Asparagus } \\
\text { solids (w/w) }\end{array}$ & $\begin{array}{l}\text { Maltodextrin } \\
(w / w)\end{array}$ & $\begin{array}{l}\text { Total } \\
\text { solids (w/ } \\
\text { w) }\end{array}$ & $\begin{array}{l}\text { Inlet } \\
\left({ }^{\circ} \mathrm{C}\right)\end{array}$ & $\begin{array}{l}\text { Outlet } \\
\left({ }^{\circ} \mathrm{C}\right)\end{array}$ \\
\hline $1: 0$ & 22 & 0 & 22 & 160 & $90-95$ \\
\hline $2: 1$ & 20 & 10 & 29 & 160 & $90-95$ \\
\hline $1: 1$ & 18 & 18 & 36 & 160 & $90-95$ \\
\hline $1: 2$ & 15 & 30 & 45 & 160 & $90-95$ \\
\hline $1: 2^{*}$ & 12 & 24 & 36 & 160 & $90-95$ \\
\hline $1: 1$ & 18 & 18 & 36 & 180 & 105 \\
\hline $1: 1$ & 18 & 18 & 36 & 180 & 90 \\
\hline
\end{tabular}




\subsection{Glass transition temperature $\left(T_{g}\right)$}

The $T_{g}$ of the spray-dried powders was determined using differential scanning calorimetry (DSC) (DSC-250, TA Instruments, New Castle, England). In addition, the $\mathrm{T}_{\mathrm{g}}$ of asparagus concentrate was determined after pre-drying the concentrate in a climate chamber (Memmert, Germany) at $25{ }^{\circ} \mathrm{C}$ and relative humidity of $10 \%$ for $24 \mathrm{~h}$. Samples of about $5 \mathrm{mg}$ were weighed in aluminium Tzero pans which were then hermetically sealed. Temperature ramp measurements were carried out at a rate of $10{ }^{\circ} \mathrm{C} / \mathrm{min}$, and the temperature range was set between $-60{ }^{\circ} \mathrm{C}$ and $140{ }^{\circ} \mathrm{C}$ depending on the moisture content of the sample. The DSC thermograms were analysed using Trios software (TA Instruments, New Castle, England). The $\mathrm{T}_{\mathrm{g}}$ was determined from the midpoint, which was based on the inflection of the endothermic shift due to glass transition, i. e. the peak of the derivative. After the temperature ramp measurements, a hole was punched in the lid of the pans and the moisture content of the sample was determined by drying the samples overnight at $105^{\circ} \mathrm{C}$. All measurements were in duplicate and the mean values of the measured results were reported.

\subsection{Particle size distribution and morphology}

The particle size distribution of the spray-dried powders was measured using a Mastersizer 3000 analyser (Malvern Inc, Worcestershire, UK) with the dry powder disperser Aero S. The particle size distribution was determined with the Mastersizer 3000 software and presented on a volume basis. Dried particles were visualised using scanning electron microscopy (SEM). The powders were attached to SEM stubs using carbon adhesive tabs, sputter-coated with gold under vacuum, and examined using a Neoscope JCM-7000 (JEOL, USA). SEM was carried out at $10 \mathrm{kV}$ with a magnification of $\times 1600$.

\subsection{Preparation of liquid samples}

Before headspace analysis of the spray-dried powders, the influence of maltodextrin on the gas/liquid-equilibrium in liquid samples was evaluated. Samples were prepared by dissolving maltodextrin DE12 in water at different concentrations, followed by mixing of the maltodextrin solutions with concentrated asparagus juice. The resulting mixtures contained maltodextrin concentrations of $0,15,25,34$ and $44 \%$. The $\mathrm{pH}$ of all mixtures was measured. The $\mathrm{pH}$-values obtained were the same for all mixtures, thus $\mathrm{pH}$ could not influence the gas/liquid partition coefficient in this study. All samples contained the same amount of asparagus solids, i.e. $30 \mathrm{mg}$, and had similar total weight. The samples were stored at $-80{ }^{\circ} \mathrm{C}$ before analysis of volatile compounds. The volatile compounds were measured according to the method described in section 2.7.2.

\subsection{Headspace analysis of volatile compounds}

\subsubsection{Sample preparation for concentrate, mix and spray-dried powder}

Volatile compounds in the defrosted asparagus concentrate, maltodextrin-asparagus concentrate mixtures and spray-dried asparagus powders were analysed by GC-MS. Samples were weighed (mass in mg) based on equation (1), i.e. all the samples contained $30 \mathrm{mg}$ dry weight of asparagus solids.

mass $=\frac{30}{X_{s} X_{a(d b)}}$

Where $\mathrm{X}_{\mathrm{S}}$ ( $\mathrm{kg}$ solids $/ \mathrm{kg}$ total) is the total solids content of the sample determined via moisture content analysis. $\mathrm{X}_{\mathrm{a}(\mathrm{db})}$ (kg asparagus solids $/ \mathrm{kg}$ solids) is the fraction of asparagus solids in the solids content of the sample, which can be derived from the mass ratio between asparagus solids and maltodextrin. For example, $X_{\mathrm{a}}$ of 2:1 ratio equals 0.67 . For a 2:1 ratio dry sample with a moisture content of $10 \% \mathrm{w} / \mathrm{w}$ (i.e., $\mathrm{X}_{\mathrm{s}}=$
0.90), the sample weight for GC-MS analysis was $50 \mathrm{mg}$.

In addition, quality controls (QCs) were prepared from a mix of the spray-dried powders, except for the 1:0 ratio since there was too little sample. All samples were transferred to $10 \mathrm{ml}$ glass vials which were subsequently stored at $-80{ }^{\circ} \mathrm{C}$ until experimentation. Before analysis, EDTA and $\mathrm{CaCl}_{2}$ were added to the samples giving a final concentration of $50 \mathrm{mM}$ and $5 \mathrm{M}$, respectively. In the case of liquid samples (asparagus concentrate, mix) solid $\mathrm{CaCl}_{2}$ was added first and subsequently the EDTA solution to a final volume of $1 \mathrm{ml}$. In the case of the dry samples (spray-dried powders), a saturated solution of $50 \mathrm{mM}$ EDTA $-5 \mathrm{M} \mathrm{CaCl}_{2}$ was added to a final volume of $1 \mathrm{ml}$.

\subsection{Headspace analysis}

Volatile compounds were extracted from the headspace using solidphase microextraction (SPME). A PDMS/DVB/CAR (Polydimethylsiloxane/Divinylbenzene/Carboxen) 50/30 $\mu \mathrm{m}$ diameter, $1 \mathrm{~cm}$ length (Supelco, PA, USA) fibre was used. The samples were incubated at $50{ }^{\circ} \mathrm{C}$ for $15 \mathrm{~min}$ with agitation. Subsequently, volatiles were trapped by exposing the fibre to the headspace of the vial for $15 \mathrm{~min}$ at $50{ }^{\circ} \mathrm{C}$ without agitation. The fibre was then thermally desorbed in the injector containing an empty glass liner (1 mm ID) (CIS4, Gerstel, Germany) at $250{ }^{\circ} \mathrm{C}$ for $2 \mathrm{~min}$ with a helium flow of $1 \mathrm{ml} / \mathrm{min}$ onto the GC column, in splitless mode. Sample handling was fully automated using a Gerstel MPS-2 autosampler using Gerstel MAESTRO software version 3.2. Analysis of the trapped volatiles was carried out on an Agilent GC7890A coupled to a 5975C quadrupole mass spectrometer. The column used was a Zebron ZB-5MSplus with dimensions $30 \mathrm{~m} \times 0.25 \mathrm{~mm} \times 1.00 \mu \mathrm{m}$ (Phenomenex). The GC oven temperature was programmed starting at $45^{\circ} \mathrm{C}$ for $2 \mathrm{~min}$, then increased at a rate of $8{ }^{\circ} \mathrm{C} / \mathrm{min}$ to $250{ }^{\circ} \mathrm{C}$ and then at a rate of $15^{\circ} \mathrm{C} / \mathrm{min}$ to $280^{\circ} \mathrm{C}$ and maintained at $280^{\circ} \mathrm{C}$ for $3 \mathrm{~min}$. The carrier gas was helium, at a constant flow rate of $1 \mathrm{ml} / \mathrm{min}$. The column effluent was ionised by electron impact at $70 \mathrm{eV}$, in the scan range $\mathrm{m} / \mathrm{z}$ 33-330. The interface temperature was set to $280{ }^{\circ} \mathrm{C}$. The retention indices (RIs) were calculated based on a series of n-alkanes (C6-C21) injected at the same conditions as the samples.

GC-MS raw data were processed using an untargeted metabolomics workflow. MetAlign software was used for baseline correction and alignment of the mass signals ( $/ \mathrm{N}>3$ ) (Lommen, 2009). Mass spectra were reconstructed to potential clusters using MSClust (Tikunov et al., 2012). Metabolites were putatively identified by matching the obtained mass spectra and RIs with those in commercial and in-house libraries (e. g. NIST17). The level of identification given to the detected compounds follows the guidelines of the Metabolomics Standards Initiative (Sumner et al., 2007). Compounds with level 4 of identification are characterised as 'unknowns' and further investigation is required for their identification. Before the statistical analysis, zero values in the processed data were randomised around the limit of detection as determined by MetAlign. Subsequently, SIMCA 15.0.2. (Umetrics, Sartorius Stedim Data Analytics $\mathrm{AB}$, Umeå, Sweden) was used to perform principal component analysis (PCA) after log 10 transformation and Pareto scaling.

\subsection{Volatile retention}

All mixes and respective spray-dried powder were analysed with SPME-GCMS. The volatile retention of each independent sample was calculated based on the ratio of the spray-dried powder with the corresponding mix (Eq. (2)). The retention was reported as the average retention of the triplicates with standard deviations.

retention $(\%)=\frac{\text { Peak intensity }\left(_{(\text {spray }- \text { dried })}\right.}{\text { Peak intensity }} \cdot 100$

The spray-dried powders were reconstituted to the same maltodextrin concentration as the mix for the headspace analysis, therefore we could safely assume the partition coefficients for the volatiles were 
similar.

\subsection{Statistical analysis}

All experiments were conducted at least in duplicate and results were presented as mean \pm standard deviations. One-way analysis of variance (ANOVA) and Tukey's HSD post hoc test were performed, and $\mathrm{p} \leq 0.05$ meant the difference between groups was statistically significant. In the case of unequal variances, the Games-Howell post hoc test was used. All statistical analyses were performed with SPSS Statistics (SPSS 25; IBM, USA).

\section{Results and discussion}

\subsection{Physical properties}

\subsubsection{Moisture content}

Moisture contents were measured for the different spray-dried powders (Table 2). The moisture content of powder dried from a 2:1 asparagus solids to maltodextrin ratio was found to be higher than that of the 1:2 ratio sample. By increasing the amount of maltodextrin before drying, the total solids content is necessarily increased. Both the maltodextrin concentration and the total solid content of the feed solution were expected to affect the properties of the spray-dried asparagus powder. To separate these effects, the 1:2* sample was also analysed, which was diluted with water to give a similar total solids content as the $1: 1$ ratio sample.

Diluting the sample from 45 to $36 \% \mathrm{w} / \mathrm{w}$ initial dry matter, i.e. 1:2 and $1: 2^{*}$, did not significantly affect the residual moisture content of the obtained powders (see Table 2). It can be argued that the 1:2 and 1:2* samples should follow a similar drying curve, in which mostly the constant rate period will be longer for the diluted concentrate. Nevertheless, the equilibrium moisture constant is the same for these powders.

Spray drying of the $1: 1$ and the $1: 2 *$ samples with the same initial dry matter (i.e. $36 \% \mathrm{w} / \mathrm{w}$ ) however resulted in a significant difference in residual moisture content. When maltodextrin is added, the hygroscopicity of the solids is affected, which influences the residual moisture content. These observations are in line with the study of Grabowski et al. (2006), who investigated the influence of varying maltodextrin-matrix ratios in spray drying of sweet potato puree. An increased maltodextrin concentration in their feed resulted in lower residual moisture contents, even at low maltodextrin concentrations (0, 10 and $20 \%$ on dry basis). Furthermore, the drying conditions influence the residual moisture content in the powder. Higher inlet air temperatures and smaller temperature differences between the inlet and outlet air $\Delta \mathrm{T}$ $\left(\mathrm{T}_{\text {in }}-\mathrm{T}_{\text {out }}\right)$ generally result in powders with lower moisture content (Reineccius, 2004). The residual moisture content of the powders

\section{Table 2}

Effects of asparagus solids to maltodextrin ratio and spray drying conditions on the moisture content and the glass transition temperature of the asparagus powder.

\begin{tabular}{llll}
\hline $\begin{array}{l}\text { Solids ratio } \\
\text { Asparagus: } \\
\text { MD12 }\end{array}$ & $\begin{array}{l}\mathrm{T}_{\text {in }} / \mathrm{T}_{\text {out }} \\
\left({ }^{\circ} \mathrm{C} /{ }^{\circ} \mathrm{C}\right)\end{array}$ & $\begin{array}{l}\text { Residual moisture } \\
\text { content }(\% \mathrm{w} / \mathrm{w})\end{array}$ & $\begin{array}{l}\text { Glass transition } \\
\text { temperature }\left({ }^{\circ} \mathrm{C}\right)\end{array}$ \\
\hline $1: 0$ & $160 / 90-95$ & $20.00^{* *}$ & - \\
$2: 1$ & $160 / 90-95$ & $15.03 \pm 0.15^{\mathrm{a}}$ & $4.18 \pm 0.76^{\mathrm{a}}$ \\
$1: 1$ & $160 / 90-95$ & $8.91 \pm 0.24^{\mathrm{b}}$ & $28.07 \pm 0.24^{\mathrm{b}}$ \\
$1: 2$ & $160 / 90-95$ & $5.24 \pm 0.17^{\mathrm{c}}$ & $44.47 \pm 14.14^{\mathrm{abc}}$ \\
$1: 2^{*}$ & $160 / 90-95$ & $5.49 \pm 0.51^{\mathrm{c}}$ & $55.01 \pm 0.11^{\mathrm{c}}$ \\
$1: 1$ & $180 / 105$ & $8.84 \pm 0.18^{\mathrm{b}}$ & $28.61 \pm 0.73^{\mathrm{b}}$ \\
$1: 1$ & $180 / 90$ & $9.33 \pm 0.22^{\mathrm{b}}$ & $24.10 \pm 1.17^{\mathrm{b}}$ \\
\hline
\end{tabular}

Note: The values followed by different lowercase letters (a-c) within a column are significantly different at $\mathrm{p} \leq 0.05$. * The $1: 2$ * samples were diluted to obtain a similar total solids content before spray drying as the 1:1 ratio. ** The sample quantity was too low to analyse the moisture content; therefore an estimated value is reported. spray-dried at $180 / 105\left(\mathrm{~T}_{\mathrm{in}} / \mathrm{T}_{\text {out }}\right)$ seems somewhat lower compared to $180 / 90$ (Table 2), however, this difference was not statistically significant.

\subsubsection{Glass transition temperature}

The formation of glassy powder particles is necessary to effectively encapsulate volatile compounds, to avoid fouling in the equipment and to obtain a free-flowing powder (Roos, 2010). Therefore, the glass transition temperatures of the different spray-dried powders were measured (Table 2). The $\mathrm{T}_{\mathrm{g}}$ of a powder is influenced by both its solids composition and its moisture content, and it is difficult to decouple those. With larger moisture content or less maltodextrin, lower $\mathrm{T}_{\mathrm{g}}$ values are found. The $T_{g}$ values of the 1:1 ratio powders spray-dried at different conditions were not significantly different. This was expected because the composition of those samples was the same and the residual moisture content in the powders was similar.

The effects of solid composition and residual moisture content on the $\mathrm{T}_{\mathrm{g}}$ were evaluated with the Couchman-Karasz equation for multicomponent mixtures (Eq. (3)), previously described by Bhandari \& Howes (1999).

$T_{g}=\frac{X_{w} C_{p, w} T_{g, w}+X_{m} C_{p, m} T_{g, m}+X_{a} C_{p, a} T_{g, a}}{X_{w} C_{p, w}+X_{m} C_{p, m}+X_{a} C_{p, a}}$

Where $\mathrm{X}_{\mathrm{w}}, \mathrm{X}_{\mathrm{m}}$ and $\mathrm{X}_{\mathrm{a}}$ are the weight fractions of water, maltodextrin and asparagus solids on wet basis. $\Delta c_{p, w}, \Delta c_{p, m}$ and $\Delta c_{p, a}$ represent the heat capacity change at glass transition of water, maltodextrin and asparagus solids, respectively. $\mathrm{T}_{\mathrm{g}, \mathrm{w}}, \mathrm{T}_{\mathrm{g}, \mathrm{m}}$ and $\mathrm{T}_{\mathrm{g}, \mathrm{a}}$ are the glass transition temperatures of water $(138 \mathrm{~K})$, maltodextrin DE12 and the asparagus solids, respectively.

Equation (3) can be rewritten to Equation (4) with $\mathrm{k}_{1}$ equals $\Delta \mathrm{c}_{\mathrm{p}, \mathrm{m}} /$ $\Delta \mathrm{c}_{\mathrm{p}, \mathrm{w}}$ and $\mathrm{k}_{2}$ equals $\Delta \mathrm{c}_{\mathrm{p}, \mathrm{a}} / \Delta \mathrm{c}_{\mathrm{p}, \mathrm{w}}$, which is often referred to as the Gordon-Taylor equation:

$T_{g}=\frac{X_{w} T_{g, w}+k_{1} X_{m} T_{g, m}+k_{2} X_{a} T_{g, a}}{X_{w}+k_{1} X_{m}+k_{2} X_{a}}$

Two coefficients $\mathrm{k}_{2}$ and $\mathrm{T}_{\mathrm{g}, \mathrm{a}}$ were estimated based on Gordon-Taylor equation (Eq. (4)) using experimental data, whereas other parameter values were obtained from literature. Specifically, for water a $\Delta \mathrm{c}_{\mathrm{p}, \mathrm{w}}$ value of $1.91 \mathrm{~kJ} \mathrm{~kg}^{-1} \cdot \mathrm{K}^{-1}$ was used and for maltodextrin a $\Delta \mathrm{c}_{\mathrm{p}, \mathrm{m}}$ value of $0.425 \mathrm{~kJ} \mathrm{~kg}{ }^{-1} \cdot \mathrm{K}^{-1}$ (Siemons et al., 2020). The anhydrous $\mathrm{T}_{\mathrm{g}}$ of maltodextrin DE12 $\left(\mathrm{T}_{\mathrm{g}, \mathrm{m}}\right)$ was $426 \mathrm{~K}\left(153^{\circ} \mathrm{C}\right)$ (Siemons et al., 2020).

We obtained a good fit $\left(\mathrm{R}^{2}=0.95\right)$ and estimated a $\mathrm{T}_{\mathrm{g}, \mathrm{a}}$ of $32^{\circ} \mathrm{C}$ and a $\mathrm{k}_{2}$ of 0.48 (Fig. 1). The $\mathrm{T}_{\mathrm{g}, \mathrm{a}}$ can be roughly related to its composition as described in the Materials and Methods, i.e. fructose $\left(10{ }^{\circ} \mathrm{C}\right)$, glucose $\left(36^{\circ} \mathrm{C}\right)$ and sucrose $\left(67^{\circ} \mathrm{C}\right)\left(\right.$ Roos, 1993). The $\Delta \mathrm{c}_{\mathrm{p}, \mathrm{a}}$ of $0.91 \mathrm{~kJ} \mathrm{~kg}{ }^{-1} \cdot \mathrm{K}^{-1}$ was derived from the $\mathrm{k}_{2}$ value and is slightly higher than reported values for mono- and disaccharides, e.g. fructose $\left(0.75-0.84 \mathrm{~kJ} \mathrm{~kg}{ }^{-1} \cdot \mathrm{K}^{-1}\right)$, glucose $\left(0.63-0.88 \mathrm{~kJ} \mathrm{~kg}^{-1} \cdot \mathrm{K}^{-1}\right)$ and sucrose $\left(0.60-0.77 \mathrm{~kJ} \mathrm{~kg}^{-1} \cdot \mathrm{K}^{-1}\right)$ (Roos, 1993).

Concerning storage, it is desired to obtain a powder in the glassy state at ambient temperatures (Roos, 2010). When the powder shifts from a glassy to a rubbery state, undesired effects may occur, such as sticking, agglomeration and volatile loss (Bonazzi \& Dumoulin, 2011). Based on our findings, only the samples prepared with asparagus solids to maltodextrin ratios of $1: 2$ or asparagus weight fraction $\leq 0.33$ (Fig. 1) reached a sufficiently high $\mathrm{T}_{\mathrm{g}}$ to be stored at ambient conditions. This model could potentially be used to estimate the $T_{g}$ of asparagus powder in future when other carrier agents are used.

\subsubsection{Particle size distribution}

The particle size distribution of all powders was analysed (Fig. 2A). Larger powder particle sizes $(100-2000 \mu \mathrm{m})$ can be explained by undesired agglomeration. Specifically, agglomeration was observed for the 2:1 ratio of asparagus solids to maltodextrin powder. This sample also had the highest residual moisture content $(15.0 \% \mathrm{w} / \mathrm{w})$, which 

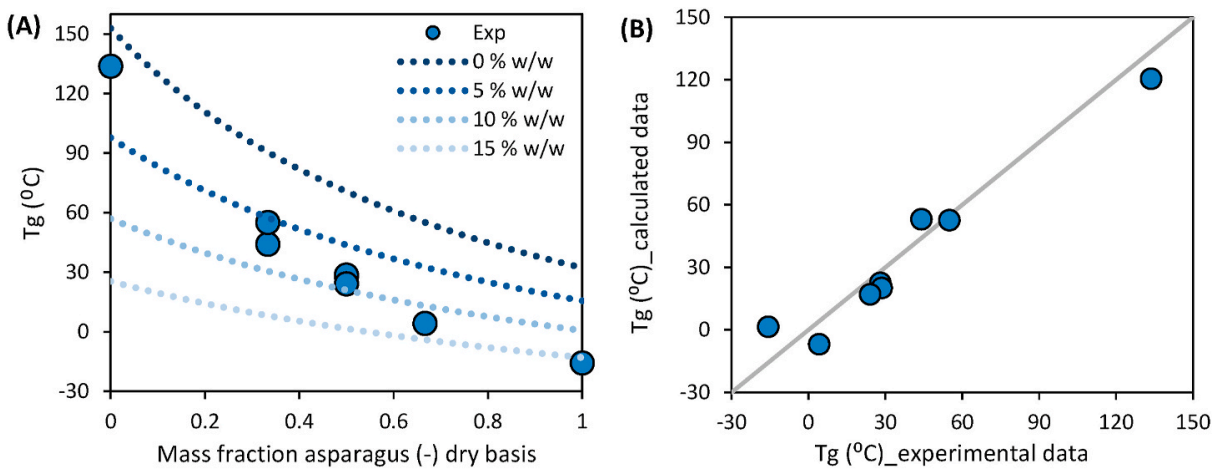

(A)

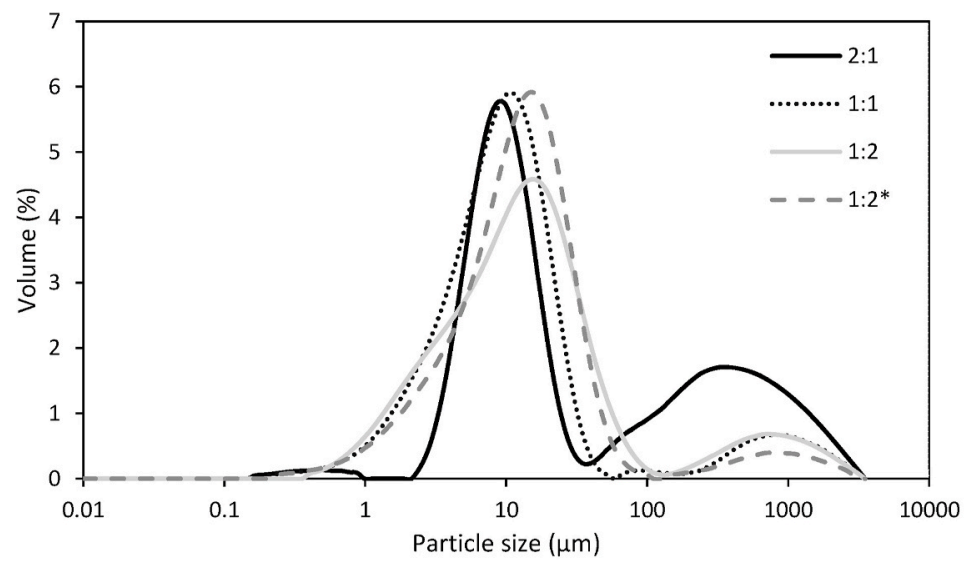

(B)
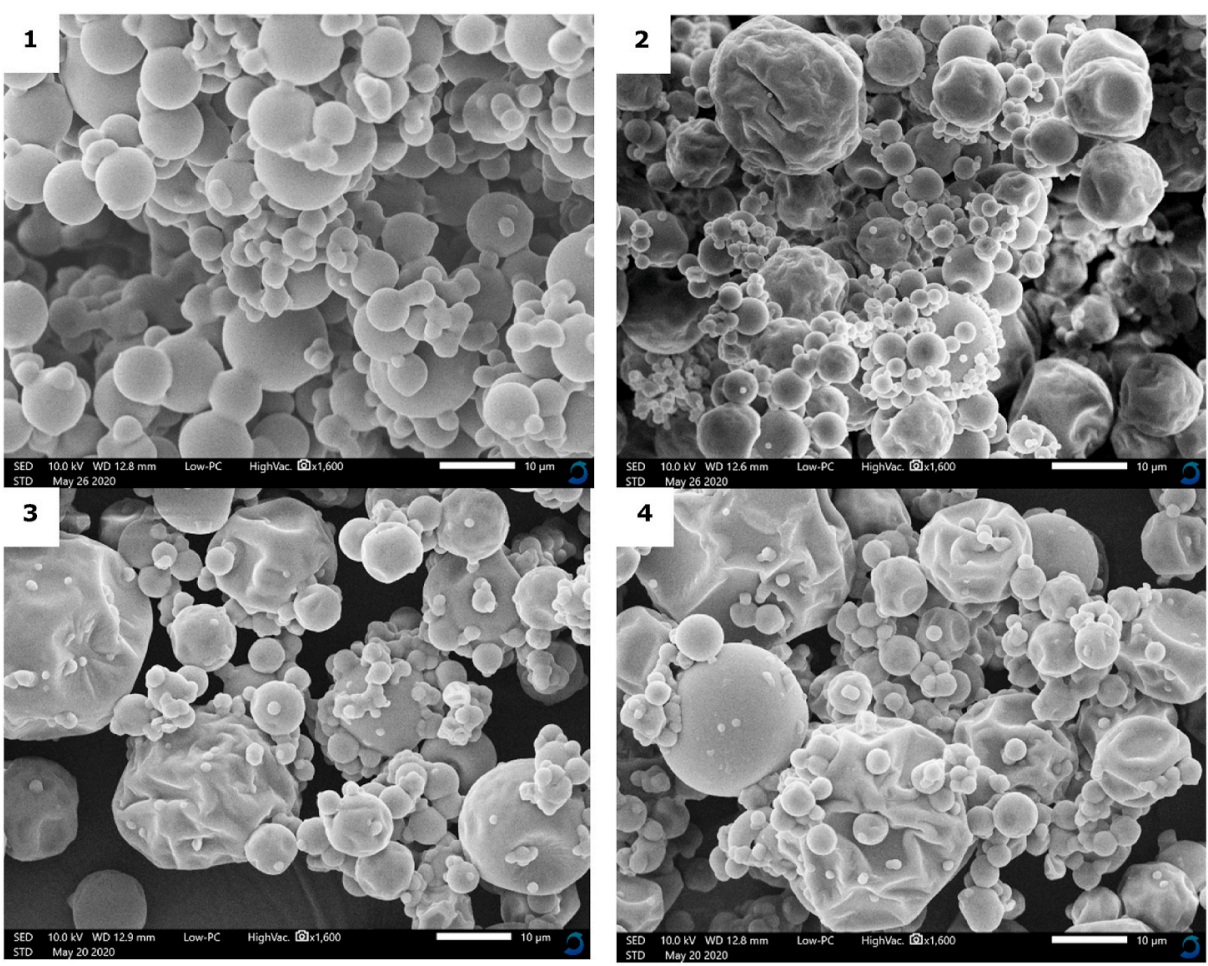

Fig. 1. (A) The glass transition temperature of spray-dried asparagus concentrate as a function of the mass fraction of asparagus (dry basis). The experimental data is fitted with the CouchmanKarasz equation for multicomponent mixtures (dotted lines) for different residual moisture contents $(0.5,10,15 \% \mathrm{w} / \mathrm{w})$. Residual moisture contents of the experimental data can be found in Table 1 . For the data point with asparagus weight fraction of $0, T_{g}$ value of a spray-dried maltodextrin solution $(30 \% \mathrm{w} / \mathrm{w})$ without asparagus concentrate was reported. For the data point with asparagus weight fraction of $1, T_{g}$ value of liquid asparagus concentrate that was pre-dried in a climate chamber at $10 \% \mathrm{RH}$ was reported. (B) The parity plot of the experimental and the calculated values of $\mathrm{T}_{g}$ based on the model.

Fig. 2. (A) Particle size distribution of spray-dried asparagus powders with different asparagus solids to maltodextrin ratios dried at $\mathrm{T}_{\mathrm{in}} / \mathrm{T}_{\text {out }}$ of $160 / 90$. The $1: 2$ * samples were diluted to obtain a similar total solids content before spray drying as the 1:1 ratio. (B) Powder morphology of spray-dried asparagus powders with asparagus solids to maltodextrin ratios 2:1 (B1), 1:1 (B2), 1:2 (B3) and 1:2* (B4). The $1: 2^{*}$ samples were diluted to obtain a similar total solids content before spray drying as the 1:1 ratio. All powders were spray-dried at 160/ $90\left(\mathrm{~T}_{\text {in }} / \mathrm{T}_{\text {out }}\right)$. Bar $=10 \mu \mathrm{m}$. 
stimulated agglomeration of the powder particles. A slight shift towards larger particle sizes can be observed with an increase in maltodextrin content. The highest peaks of the 2:1 ratio, $1: 1$ ratio and 1:2 ratio samples were found to correspond to a particle size of ca. $8 \mu \mathrm{m}, 10 \mu \mathrm{m}$ and $15 \mu \mathrm{m}$, respectively. This increase in average particle size may be explained by the generation of larger droplets during atomization due to the increase of the feed viscosity with the addition of maltodextrin (Bangs \& Reineccius, 1982; Reineccius, 2004).

The results of the 1:1 ratio dried at different inlet and outlet temperature combinations were found to be similar (data not shown),

(A)
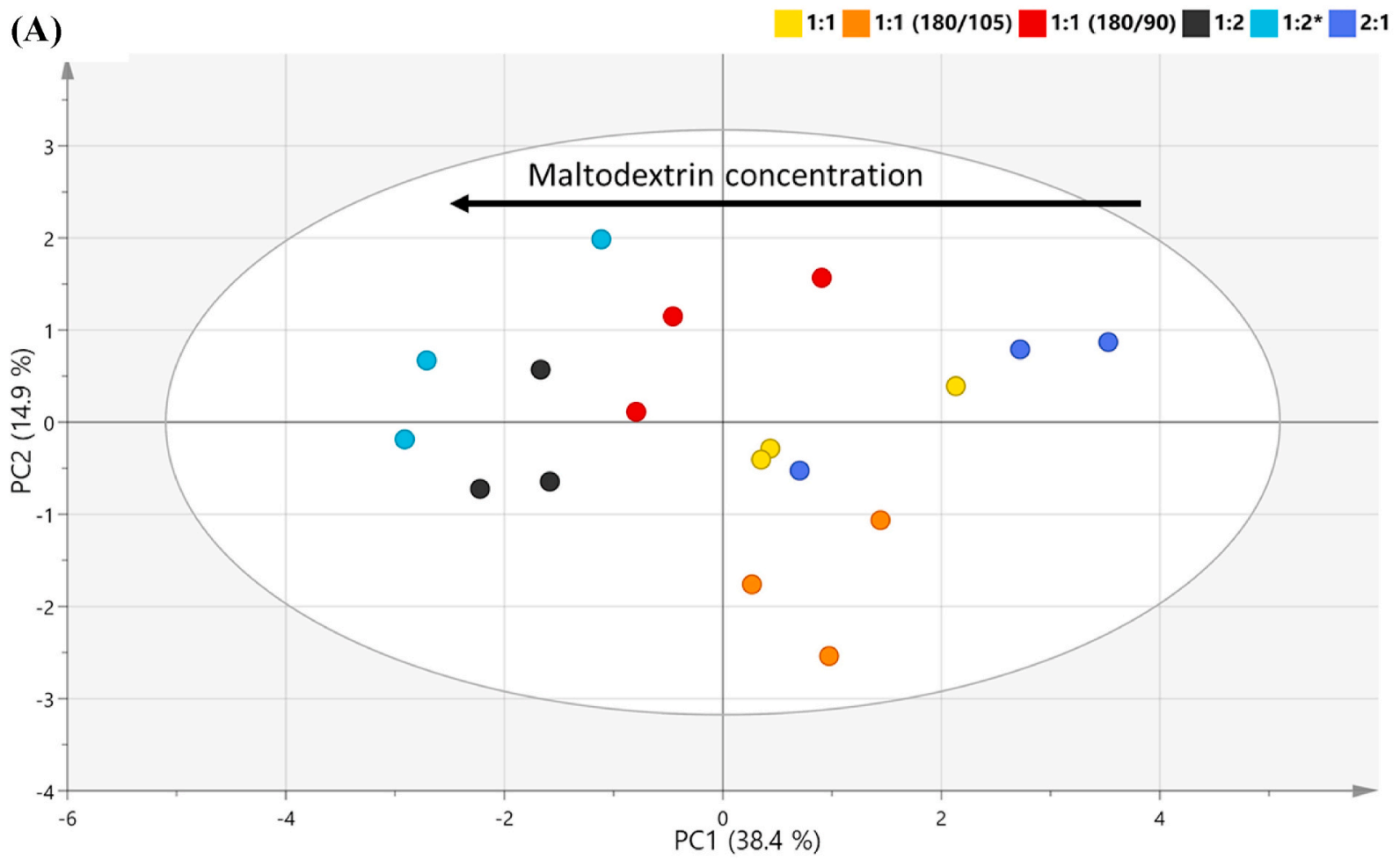

(B)

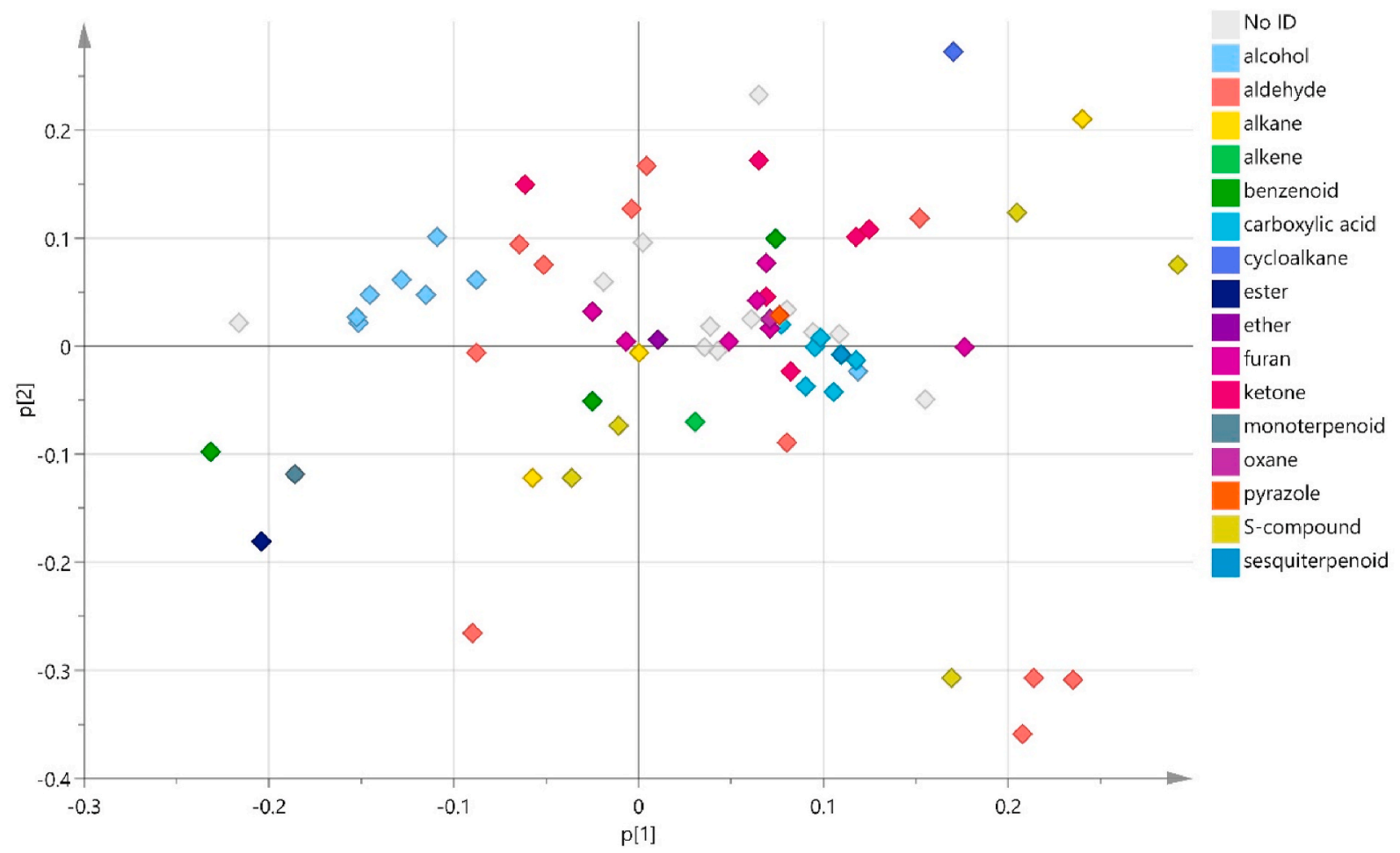

Fig. 3. (A) Score plot of the volatile profiles of the spray-dried samples prepared with maltodextrin. The score plot is based on 70 volatiles. The colours indicate the ratio of asparagus solids to maltodextrin. The samples were spray-dried at $\mathrm{T}_{\text {in }} / \mathrm{T}_{\text {out }}$ of $160 / 90$, unless stated otherwise. (B) The loading plot corresponding to the PCA score plot. (For interpretation of the references to colour in this figure legend, the reader is referred to the Web version of this article.) 
indicating no significant effect of drying conditions on particle size distribution in this study.

\subsubsection{Morphology}

Different particle morphologies such as smooth round and dented particles were observed for the spray-dried powders (Fig. 2B). Similar dented structures for MD12 were previously observed by Both et al. (2018) and Siemons et al. (2020). For the 2:1 ratio of asparagus solids to maltodextrin (Fig. 2-B1), only small spherical particles with a smooth surface were present in the powder. It is suggested that the high concentration of small sugars from the asparagus concentrate allows more shrinkage of the droplets which results in smoother and more spherical particles. This is also in agreement with Paramita et al. (2010) who observed that replacement of maltodextrin DE 11 by trehalose also provided smoother particles.

The influence of the different spray drying conditions on the morphology appeared to be minor (data not shown). All powders had both smooth and dented particles and the particle sizes appear similar based on the SEM images.

\subsection{Analysis of asparagus aroma compounds}

To study the influence of maltodextrin on the volatile compounds after spray drying, first the overall volatile profiles of asparagus concentrate samples before and after spray drying were compared. Processing of the GC-MS raw data and manual filtering of system artefacts resulted in a list of 70 compounds that were further analysed. Identification was focused on the known key asparagus volatiles from literature (Pegiou et al., 2019).

Principal components analysis (PCA) was performed to obtain a general overview of the samples and how their volatiles composition differ. PCA on all the samples showed that PC1 separates the spray-dried powder and the concentrate/mix before drying, indicating a clear difference in the volatile profiles (Supplementary data, Figure A1). The QCs consisting of a mix of spray-dried powders were analysed to determine technical variability. The QCs group together in the PCA plot, indicating a low technical variation of the measurements. To get a better view of the difference between the powders, PCA was performed on all the spray-dried powder samples with and without maltodextrin (Supplementary data, Figure A2). The first two PCs explain 48\% and 19.6\% of the total variation, respectively. The variation on PC1 can be attributed to the different ratios of maltodextrin used. This is more obvious from Fig. 3A, where the PCA was performed on the spray-dried powders containing the different concentrations of maltodextrin. Here the first PC explains $38.4 \%$ of the variation between powder samples. The black arrow indicates that spray-dried powders with higher maltodextrin concentrations move towards the negative $\mathrm{x}$-axis.

The loading plot (Fig. 3B) shows that the influence of maltodextrin concentration on the retention of aromas is dependent on their molecular properties. Focusing on the PC1, we can see that mainly alcohols and aldehydes were higher present with higher concentrations of maltodextrin. Sulphur-containing volatile compounds (S-compounds) were higher present with lower maltodextrin concentrations, while carboxylic acids, ethers and furans were not significantly affected by the maltodextrin concentration.

Among these 70 compounds, some compounds were previously identified as asparagus aromas including 3-methylthio-propanal, 1octen-3-ol, 1-pentanol, octanal and dimethyl sulphide (Tressl, Holzer, \& Apetz, 1977; Ulrich et al., 2001). Some of these compounds, such as 1-octen-3-ol and octanal, are present in the asparagus concentrate and we aim to retain those during spray drying. Other compounds, e.g. dimethyl sulphide and 3-methylthio-propanal, are formed upon drying. For the latter category, higher peak intensity values were found with less or no maltodextrin. Most of the compounds in the spray-dried samples are positively correlated with the increasing concentration of maltodextrin (data not shown), which suggests that maltodextrin is effective as a carrier agent. The aromas already present in asparagus as well as the aromas that are generated during asparagus processing can be of great importance to the final aroma and taste of the powder (Pegiou et al., 2019).

\subsubsection{Effect of maltodextrin on 1-octen-3-ol in mixtures}

One volatile compound was selected for an in-depth analysis, 1octen-3-ol. This alcohol is a key aroma in cooked asparagus conferring an earthy and mushroom-like aroma and is present in the raw asparagus as well (Pegiou et al., 2019). 1-Octen-3-ol is formed via oxidative degradation of linoleic acid, which involves the transformation of hydroperoxides into the volatile 1-octen-3-ol facilitated by cleaving enzymes (Assaf et al., 1997; Tressl, Holzer, \& Apetz, 1977). 1-Octen-3-ol was present in the asparagus concentrate at relatively high concentration, indicating that the oxidative degradation might have been initiated during the pressing and concentration of the concentrate.

The influence of maltodextrin solutions on the partitioning of volatile compounds between the gas/liquid phases has been investigated before. Chung and Villota (1990) found that the concentration of butanol in the gas phase decreased when the maltodextrin content was increased. They suggested that maltodextrin forms aggregates with hydrophobic portions on the inside and these hydrophobic portions interact with butanol and other hydrophobic compounds. Jouquand et al. (2004) also stated that the retention of aroma compounds by maltodextrin is linked to the hydrophobicity of aroma compounds. In our study, we evaluated the effect of maltodextrin on the partition coefficient of 1-octen-3-ol by analysing the headspace of mixtures with equal amounts of 1-octen-3-ol and different maltodextrin concentrations. The results (Fig. 4A) indicate an inverse correlation between the measured 1-octen-3-ol in the headspace and the concentration of maltodextrin in the liquid phase. This inverse correlation is explained by the relative hydrophobicity of 1 -octen-3-ol, i.e. $\log \mathrm{P}=2.5$, and therefore enabled its complexation by maltodextrin.

\subsubsection{Effect of maltodextrin on retention of 1-octen-3-ol in spray-dried powder}

The detected peak intensities of 1-octen-3-ol in the mixes before drying and in the spray-dried powders are shown in Fig. 4B. The peak intensities in the mix were found to decrease for the higher ratios of maltodextrin, this could be explained by the effect of maltodextrin on the gas-liquid partition coefficient as discussed previously.

The peak intensities of 1-octen-3-ol were lower after spray drying, indicating that 1-octen-3-ol was partially lost during drying. Without maltodextrin (1:0) only a small amount of 1-octen-3-ol could still be detected after drying. Higher concentrations of maltodextrin increased the detection of 1-octen-3-ol. This suggests that maltodextrin DE12 retains part of the 1-octen-3-ol during spray drying, which may be explained by the reduction of the constant rate period. For the samples that were prepared with 1:2 ratios, the diluted samples (triangles) have slightly lower peak intensity after drying. The encapsulation of 1-octen3-ol may have been decreased by the lower initial solids content.

To discuss the role of maltodextrin on aroma retention, we calculated the retention of 1-octen-3-ol based on the ratio of the peak intensities of the mix and the corresponding spray-dried powder. The retention of 1 octen-3-ol increases with higher concentrations of maltodextrin (Fig. 4C). This is in line with the results by Bangs and Reineccius (1982), who evaluated the retention of twelve organic flavour compounds, including 1-octen-3-ol, in a model system with maltodextrin DE10. The overall retention increased from 23 to $80 \%$ when the maltodextrin concentration was increased from $32 \% \mathrm{w} / \mathrm{w}$ to $50 \% \mathrm{w} / \mathrm{w}$. We observe similar trends (Fig. 4C) for two other major alcohols in white asparagus, namely 1-pentanol and 1-hexanol (Tressl, Holzer, \& Apetz, 1977). To a smaller extent the retention of heptanal, an aldehyde previously detected in green asparagus juice (Chen et al., 2015), benefitted from an increase in maltodextrin. 


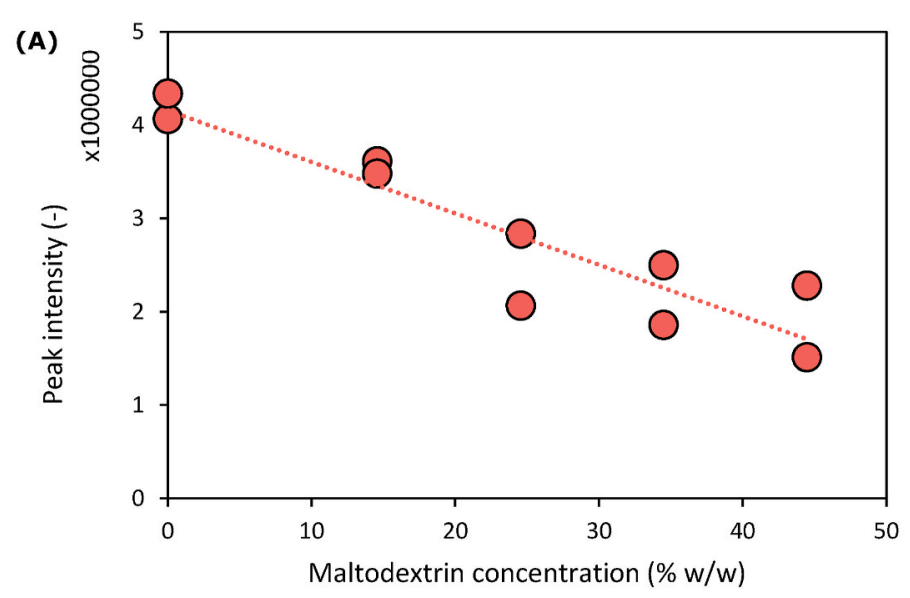

(B)

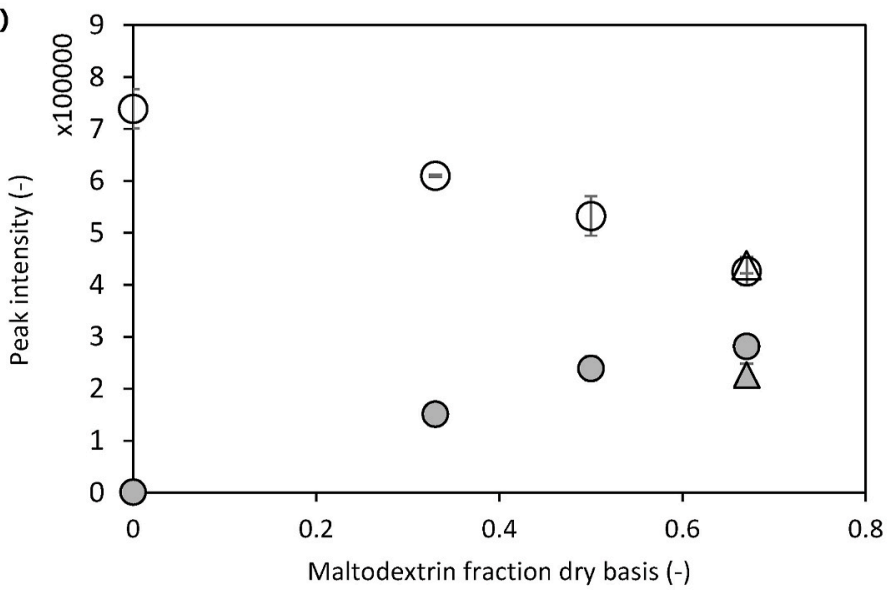

(C)

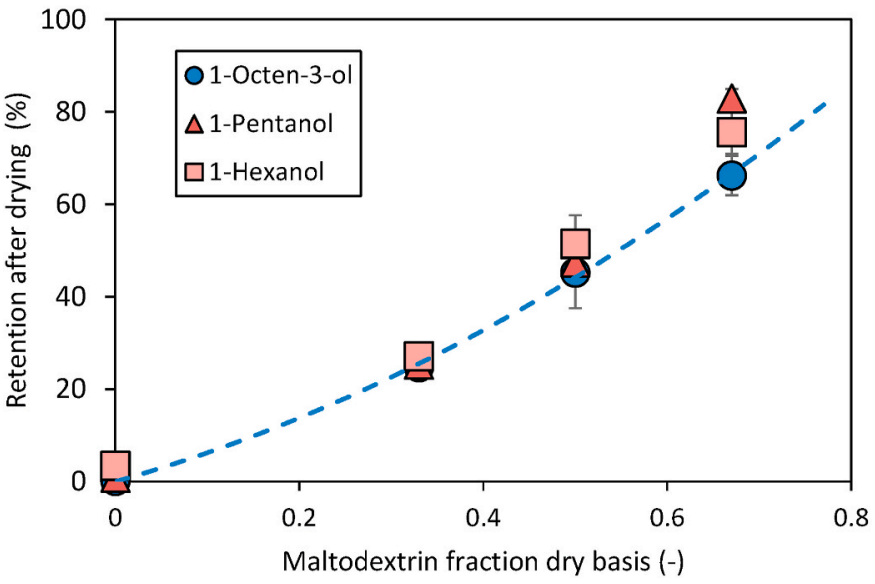

Fig. 4. (A) The peak intensity of 1-octen-3-ol measured by SPME in asparagus concentrate prepared with different maltodextrin concentrations (results from two independent experiments were shown). (B) The peak intensity profiles of 1-octen-3ol before (white circles) and after spray drying (grey circles) for asparagus concentrate prepared with different asparagus solids to maltodextrin ratios. The triangles indicate the samples $1: 2^{*}$, which were diluted with water to give a similar initial solids content as the 1:1 ratio sample. All samples were spray-dried at $T_{\text {in }} / T_{\text {out }}$ of $160 / 90$. The error bars represent the standard deviation of the experimental data $(\mathrm{n}=3)$. (C) The retention after drying of 1-octen-3-ol, 1-pentanol and 1-hexanol. The dashed line is drawn to guide the eye for 1-octen-3ol. The samples were prepared with different asparagus solids to maltodextrin ratios and spraydried at $\mathrm{T}_{\text {in }} / \mathrm{T}_{\text {out }}$ of $160 / 90$. The retention of the volatile compounds was calculated based on the peak intensities of the mix before drying and the spray-dried powder. The error bars represent the standard deviation of the experimental data $(n=3)$.

OMixes

OSpray-dried powders

$\Delta 1: 2^{*}$ (mix)

$\Delta 1: 2^{*}$ (spray-dried)

\subsubsection{Effect of drying conditions}

Three combinations of inlet and outlet temperatures were applied during spray drying of 1:1 ratio mixtures. In Fig. 5 the abundance profiles of several compounds have been plotted. Some of the compounds in the asparagus concentrate we would like to retain during drying (e.g. 1octen-3-ol). Other compounds were not present in the concentrate and were only formed upon drying (e.g. dimethyl sulphide, 2-methylpropanal, 3-methylbutanal and 3-methylthio-propanal).

For 1-octen-3-ol, the influence of the drying conditions tested in this study had a minor influence on the measured abundance profiles. For dimethyl sulphide, there was no significant influence of inlet/outlet temperature combinations on the abundance. For 2-methylpropanal, 3methylbutanal and 3-methylthio-propanal, however, the temperature combination of 180/105 resulted in larger headspace concentration compared to $160 / 90$ and $180 / 90$. These high values after drying at 180/ 105 can be related to the high outlet temperature inducing formation of these components. Ideally, we aim to minimise the formation of volatile compounds during drying. Volatiles that are formed during drying might get lost during storage due to package permeability, consequently, flavour stability will be reduced. Instead, these volatiles should be formed while the consumer prepares the food product. 


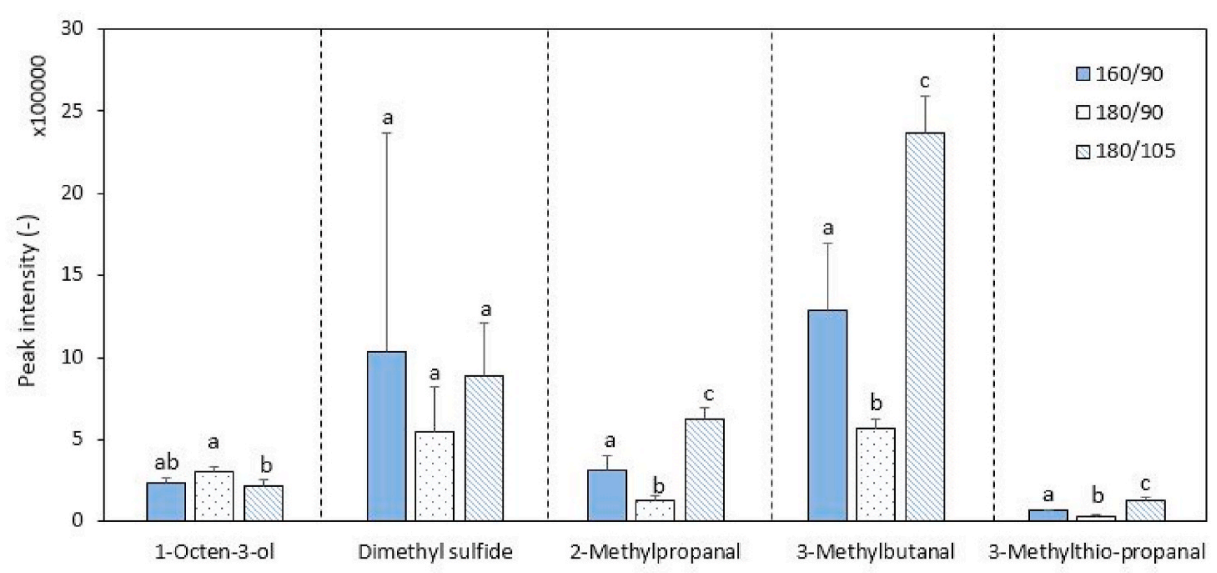

Fig. 5. Abundance of 1-octen-3-ol, dimethyl sulphide, 2-methylpropanal, 3-methylbutanal and 3-methylthio-propanal in spray-dried asparagus powder dried at different inlet and outlet temperatures $\left(\mathrm{T}_{\mathrm{in}} / \mathrm{T}_{\text {out }}\right)$. All powders were prepared with 1:1 ratio asparagus solids to maltodextrin. The error bars represent the standard deviation of the experimental data $(n=3)$. The same letters represent no significant difference $(\mathrm{p} \leq 0.05)$.

\section{Conclusions}

The influence of maltodextrin concentration and drying conditions on the physical properties and aroma retention of spray-dried asparagus was studied. Increasing maltodextrin concentration resulted in spraydried powders with a lower moisture content, higher $\mathrm{T}_{\mathrm{g}}$ and less undesired agglomeration. A ternary Gordon-Taylor equation reasonably described the effects of the composition of multicomponent mixtures and residual moisture content on the $\mathrm{T}_{\mathrm{g}}$ of asparagus powder. The drying conditions tested in this study had a minor effect on the physical properties of asparagus powder. Moreover, maltodextrin concentration in carrier formulations influenced the retention of a key flavour compound 1-octen-3-ol. Increasing maltodextrin concentration increased the retention of 1-octen-3-ol, as well as other alcohols and an aldehyde. Nevertheless, the drying conditions studied did not have a significant influence on volatile retention. Interestingly, higher outlet air temperature resulted in a higher amount of several asparagus volatiles that were formed during drying. To minimise the formation of these compounds, but also to still have enough drying capacity and avoid fouling issues, the outlet temperature should not be too high, preferably not above $90{ }^{\circ} \mathrm{C}$.

In conclusion, this study showed that maltodextrin can be used to yield maximum volatile retention after spray drying of asparagus concentrate. This is because firstly aroma compounds can form a complex with maltodextrin, and secondly, a shorter constant rate period and fast skin formation during drying could hinder evaporation of aromas when increasing maltodextrin concentration.

\section{CRediT authorship contribution statement}

Joanne W. Siccama: Conceptualization, Methodology, Formal analysis, Investigation, Writing - original draft. Eirini Pegiou: Methodology, Formal analysis, Writing - original draft. Lu Zhang: Conceptualization, Writing - review \& editing, Supervision. Roland Mumm: Methodology, Writing - review \& editing. Robert D. Hall: Methodology, Writing - review \& editing. Remko M. Boom: Writing - review \& editing, Supervision. Maarten A.I. Schutyser: Conceptualization, Supervision, Writing - review \& editing, Funding acquisition.

\section{Declaration of competing interest}

The authors declare that they have no known competing financial interests or personal relationships that could have appeared to influence the work reported in this paper.

\section{Acknowledgements}

This work took place within the framework of the Institute for Sustainable Process Technology (ISPT) under the scope of the Waste2Taste project (project number: TKITOEDR-20-11).

\section{Appendix A. Supplementary data}

Supplementary data to this article can be found online at https://doi. org/10.1016/j.lwt.2021.111058.

\section{References}

Anandharamakrishnan, C., \& Padma Ishwarya, S. (2015). Encapsulation of flavors and specialty oils. In Spray drying techniques for food ingredient encapsulation (pp. 126-155). John Wiley \& Sons, Ltd. https://doi.org/10.1002/9781118863985.ch6.

Assaf, S., Hadar, Y., \& Dosoretz, C. G. (1997). 1-Octen-3-ol and 13-hydroperoxylinoleate are products of distinct pathways in the oxidative breakdown of linoleic acid by Pleurotus pulmonarius. Enzyme and Microbial Technology, 21, 484-490. https://doi. org/10.1016/S0141-0229(97)00019-7

Bangs, W. E., \& Reineccius, G. A. (1982). Influence of dryer infeed matrices on the retention of volatile flavor compounds during spray drying. Journal of Food Science, 47, 254-259. https://doi.org/10.1111/j.1365-2621.1982.tb11072.x

Bearth, A., Cousin, M.-E., \& Siegrist, M. (2014). The consumer's perception of artificial food additives: Influences on acceptance, risk and benefit perceptions. Food Quality and Preference, 38, 14-23. https://doi.org/10.1016/J.FOODQUAL.2014.05.008

Bhandari, B. R., \& Howes, T. (1999). Implication of glass transition for the drying and stability of dried foods. Journal of Food Engineering, 40, 71-79. https://doi.org/ 10.1016/S0260-8774(99)00039-4. Elsevier.

Bonazzi, C., \& Dumoulin, E. (2011). Quality changes in food materials as influenced by drying processes. In Modern drying Technology: Product quality and formulation (pp. $1-20)$.

Both, E. M., Nuzzo, M., Millqvist-Fureby, A., Boom, R. M., \& Schutyser, M. A. I. (2018). Morphology development during single droplet drying of mixed component formulations and milk. Food Research International, 109, 448-454. https://doi.org/ 10.1016/j.foodres.2018.04.043

Chen, X., Qin, W., Ma, L., Xu, F., Jin, P., \& Zheng, Y. (2015). Effect of high pressure processing and thermal treatment on physicochemical parameters, antioxidant activity and volatile compounds of green asparagus juice. Lebensmittel-Wissenschaft und -Technologie- Food Science and Technology, 62, 927-933. https://doi.org/ 10.1016/j.lwt.2014.10.068

Chung, S., \& Villota, R. (1990). Changes in partition coefficients of alcohols as affected by the presence of various food solids. Journal of Food Process Engineering, 13, 169-189. https://doi.org/10.1111/j.1745-4530.1990.tb00066.x

Coumans, W. J., Kerkhof, P. J. A. M., \& Ruin, S. (1994). Theoretical and practical aspects of aroma retention in spray drying and freeze drying. Drying Technology, 12, 99-149. https://doi.org/10.1080/07373939408959951

Diez-Simon, C., Mumm, R., \& Hall, R. D. (2019). Mass spectrometry-based metabolomics of volatiles as a new tool for understanding aroma and flavour chemistry in processed food products. Metabolomics, 1, 41. https://doi.org/10.1007/s11306-0191493-6

Eiser, J. R., Coulson, N. S., \& Eiser, C. (2002). Adolescents' perceptions of the costs and benefits of food additives and their presence in different foods. https://doi.org/10.1080/ 13669870010004979 
Grabowski, J. A., Truong, V.-D. D., \& Daubert, C. R. (2006). Spray-drying of amylase hydrolyzed sweet potato puree and physicochemical properties of powder. Journal of Food Science, 71, E209-E217. https://doi.org/10.1111/j.1750-3841.2006.00036.x

Jouquand, C., Ducruet, V., \& Giampaoli, P. (2004). Partition coefficients of aroma compounds in polysaccharide solutions by the phase ratio variation method. Food Chemistry, 85, 467-474. https://doi.org/10.1016/j.foodchem.2003.07.023

Karam, M. C., Petit, J., Zimmer, D., Baudelaire Djantou, E., \& Scher, J. (2016). Effects of drying and grinding in production of fruit and vegetable powders: A review. Journal of Food Engineering, 188, 32-49. https://doi.org/10.1016/j.jfoodeng.2016.05.001

King, C. J. (1995). Spray drying: Retention of volatile compounds revisited. Drying Technology, 13, 1221-1240. https://doi.org/10.1080/07373939508917018

Knoema. (2019). Production Statistics - crops, crops processed [WWW document]. URL https://knoema.com/FAOPRDSC2020/production-statistics-crops-crops-processed accessed 6.8.20.

Lommen, A. (2009). MetAlign: Interface-Driven, versatile metabolomics tool for hyphenated full-scan mass spectrometry data preprocessing. Analytical Chemistry, 81, 3079-3086. https://doi.org/10.1021/ac900036d

Madene, A., Jacquot, M., Scher, J., \& Desobry, S. (2006). Flavour encapsulation and controlled release - a review. International Journal of Food Science and Technology, 41, 1-21. https://doi.org/10.1111/j.1365-2621.2005.00980.x

Nijhuis, H., Torringa, H., Muresan, S., Yuksel, D., Leguijt, C., \& Kloek, W. (1998). Approaches to improving the quality of dried fruit and vegetables. Trends in Food Science \& Technology, 9, 13-20. https://doi.org/10.1016/S0924-2244(97)00007-1

Nindo, C. I., Sun, T., Wang, S. W., Tang, J., \& Powers, J. R. (2003). Evaluation of drying technologies for retention of physical quality and antioxidants in asparagus (Asparagus officinalis, L.). Lebensmittel-Wissenschaft und -Technologie- Food Science and Technology, 36, 507-516. https://doi.org/10.1016/S0023-6438(03)00046-X

Paramita, V., Iida, K., Yoshii, H., \& Furuta, T. (2010). Effect of additives on the morphology of spray-dried powder. Drying Technology, 28, 323-329. https://doi.org/ 10.1080/07373931003627098

Pegiou, E., Mumm, R., Acharya, P., de Vos, R. C. H., \& Hall, R. D. (2019). Green and white Asparagus (Asparagus officinalis): A Source of developmental, chemical and urinary intrigue. Metabolites, 10, 17. https://doi.org/10.3390/metabo10010017

Reineccius, G. A. (2004). The spray drying of food flavors. Drying Technology, 22, 1289-1324. https://doi.org/10.1081/DRT-120038731

Roos, Y. (1993). Melting and glass transitions of low molecular weight carbohydrates. Carbohydrate Research, 238, 39-48. https://doi.org/10.1016/0008-6215(93)87004. C

Roos, Y. H. (2010). Glass transition temperature and its relevance in food processing. Annu. Rev. Food Sci. Technol, 1, 469-496. https://doi.org/10.1146/annurev. food.102308.124139

Shim, S.-M., Seo, S. H., Lee, Y., Moon, G.-I., Kim, M.-S., \& Park, J.-H. (2011). Consumers' knowledge and safety perceptions of food additives: Evaluation on the effectivenes of transmitting information on preservatives. Food Control, 22, 1054-1060. https:// doi.org/10.1016/J.FOODCONT.2011.01.001

Siccama, J., Zhang, L., \& Schutyser, M. (2019). Strategies to retain volatile compounds during convective drying. In 7th European drying conference.

Siemons, I., Politiek, R. G. A., Boom, R. M., van der Sman, R. G. M., \& Schutyser, M. A. I. (2020). Dextrose equivalence of maltodextrins determines particle morphology development during single sessile droplet drying. Food Research International, 131, 108988. https://doi.org/10.1016/j.foodres.2020.108988

Sumner, L. W., Amberg, A., Barrett, D., Beale, M. H., Beger, R., Daykin, C. A., Fan, T. W. M., Fiehn, O., Goodacre, R., Griffin, J. L., Hankemeier, T., Hardy, N., Harnly, J., Higashi, R., Kopka, J., Lane, A. N., Lindon, J. C., Marriott, P., Nicholls, A. W., ... Viant, M. R. (2007). Proposed minimum reporting standards for chemical analysis: Chemical analysis working group (CAWG) metabolomics standards initiative (MSI). Metabolomics, 3, 211-221. https://doi.org/10.1007/ s11306-007-0082-2

Thijssen, H. A. C. (1971). Flavour retention in drying preconcentrated food liquids. Journal of Chemical Technology \& Biotechnology, 21, 372-377. https://doi.org/ 10.1002/jctb.5020211208

Tikunov, Y. M., Laptenok, S., Hall, R. D., Bovy, A., \& de Vos, R. C. H. (2012). MSClust: A tool for unsupervised mass spectra extraction of chromatography-mass spectrometry ion-wise aligned data. Metabolomics, 8, 714-718. https://doi.org/10.1007/s11306011-0368-2

Tressl, R., Holzer, M., \& Apetz, M. (1977a). Formation of flavor components in asparagus. 1. Biosynthesis of sulfur-containing acids in asparagus. Journal of Agricultural and Food Chemistry, 25, 455-459.

Tressl, R., Holzer, M., \& Apetz, M. (1977b). Formation of flavor components in Asparagus. 2. Formation of flavor components in cooked Asparagus. Journal of Agricultural and Food Chemistry, 25, 459-463. https://doi.org/10.1021/jf60211a025

Ulrich, D., Hoberg, E., Bittner, T., Engewald, W., \& Meilchen, K. (2001). Contribution of volatile compounds to the flavor of cooked asparagus. European Food Research and Technology, 213, 200-204. https://doi.org/10.1007/s002170100349

Verma, A., \& Vir Singh, S. (2015). Spray drying of fruit and vegetable juices-A review. Critical Reviews in Food Sciences and Nutrition, 55, 701-719. https://doi.org/10.1080/ 10408398.2012.672939

Zhang, W., Wu, W., Wang, Q., Chen, Y., \& Yue, G. (2014). The juice of Asparagus byproduct exerts hypoglycemic activity in streptozotocin-induced diabetic rats. Journal of Food Biochemistry, 38, 509-517. https://doi.org/10.1111/jfbc.12084

Zuidam, N. J., \& Heinrich, E. (2010). Encapsulation of aroma. In Encapsulation technologies for active food ingredients and food processing (pp. 127-160). New York, NY: Springer New York. https://doi.org/10.1007/978-1-4419-1008-0_5.

\section{Key references}

Anandharamakrishnan, C., \& Padma Ishwarya, S. (2015a). Encapsulation of flavors and specialty oils. In Spray Drying Techniques for Food Ingredient Encapsulation (pp. 126-155). John Wiley \& Sons, Ltd. https://doi.org/10.1002/9781118863985.ch6.

This book chapter describes the general approach to encapsulate food flavours, the mechanism of encapsulation and the role of different carriers.

Bhandari, B. R., \& Howes, T. (1999a). Implication of glass transition for the drying and stability of dried foods. In Journal of Food Engineering. Elsevier. https://doi.org/ 10.1016/S0260-8774(99)00039-4.

This study provided the Couchman-Karasz model for multicomponent mixtures, we used this model in this research to study the relationship between composition and glass transition temperature.

Thijssen, H. A. C. (1971a). Flavour Retention in Drying Preconcentrated Food Liquids. J. Appl. Chem. Biotechnol, 21, 372-377. https://doi.org/10.1002/jctb.5020211208

This study described the role of skin formation during drying of food liquids, which is the mechanism we used to explain the encapsulation ability of maltodextrin.

Pegiou, E., Mumm, R., Acharya, P., de Vos, R. C. H., \& Hall, R. D. (2019a). Green and White Asparagus (Asparagus officinalis): A Source of Developmental, Chemical and Urinary Intrigue. Metabolites, 10, 17. https://doi.org/10.3390/metabo10010017

This review lists the key volatile compounds in white asparagus that we further analysed in this study.

Reineccius, G. A. (2004a). The Spray Drying of Food Flavors. Drying Technology, 22, 1289-1324. https://doi.org/10.1081/DRT-120038731

This review lists previous studies on spray drying of food flavours as influenced by carrier matrices and drying conditions. We based our hypothesis on the studies described in this paper. 